\title{
First Swiss bachelor in Photonics
}

\section{Tobias Leutenegger, Bruno Studer}

Tobias Leutenegger, Bruno Studer, "First Swiss bachelor in Photonics," Proc. SPIE 9793, Education and Training in Optics and Photonics: ETOP 2015, 97932H (8 October 2015); doi: 10.1117/12.2223216

SPIE Event: Education and Training in Optics and Photonics: ETOP 2015, 2015, Bordeaux, France 


\title{
First Swiss Bachelor in Photonics
}

\author{
Tobias Leutenegger*, Bruno Studer \\ University of Applied Sciences HTW Chur, Pulvermuehlestrasse 57, 7000 Chur, Switzerland
}

\begin{abstract}
Swissmem, the Swiss association of mechanical and electrical engineering industries, founded a new photonics group in 2013. This reflects the importance of this key technology for Switzerland. Swissmem requested from the Swiss Universities of Applied Sciences to introduce a new bachelor program to fulfill the increasing demand of the Swiss industry of young academics in the field of photonics. Optech Consulting is investigating the Swiss photonics market since many years on behalf of Swissphotonics, the Swiss national thematic network for photonics. The study concluded that the total production volume of the Swiss photonics industry in the year 2013 was 3 billion Swiss francs and a slight growth is expected for 2014 .

The University of Applied Science HTW Chur is located in the Eastern part of Switzerland. This area of the Rhine valley is a technology cluster of innovative companies in the field of optics and electronics. The industry is growing and the R\&D departments of the worldwide active companies are lacking well-educated photonics engineers.

The HTW Chur is dedicated to establish the first Swiss bachelor in Photonics. Supported by strong industrial players and an excellent network, the HTW Chur developed different job descriptions and a complete curriculum, which reflect the needs of the Swiss photonics industry. Almost $60 \%$ of the ECTS of this national degree program are assigned to photonics specific courses and the practical projects are organized in close collaboration with the photonics industry. Curriculum, job descriptions and the industrial needs will be discussed in detail in this paper.
\end{abstract}

Keywords: HTW Chur, Swiss bachelor in Photonics, curriculum, job descriptions, industrial needs, SWISSMEM

\section{GENERAL OVERVIEW OF PHOTONICS IN SWITZERLAND}

\subsection{Swiss photonic market}

Based on the investigations of Optech Consulting ${ }^{1}$ the Swiss photonic market was 3 billion Swiss francs in 2013 . The production volume of different market segments is given in the figure below. The largest segment is Laser material machining (27\%) followed by Optical measurement techniques and image data processing (23\%). Optech Consulting expects a small market growth for 2014 (one digit percent growth). The market volume can be compared to the photonics industry report $2013^{2}$, conducted by the German government. There, the Swiss volume is estimated to be about $10 \%$ of the volume of Germany. No value is given for the year 2013, but for 2011, the Swiss volume was 2.7 billion EUR. If an average EUR-CHF ratio of 1.25 is taken, this results in about 3.4 billion CHF. However, the study of Optech Consulting states about 4 billion CHF for 2011, leading to the conclusion that the values of the photonic industry report underestimate the Swiss market by around 17\%. The photonics report expects the German photonic market to be 44 billion EUR in the year 2020. Taking the 10\% rule for Switzerland, the expected Swiss market for 2020 will be 4.4 billion EUR. If the underestimation is taken into consideration, the Swiss photonic market for 2020 could even be 5.1 billion EUR. Anyhow, both studies show the potential of the Swiss photonic industry.

Education and Training in Optics and Photonics: ETOP 2015, edited by Eric Cormier, Laurent Sarger Proc. of SPIE Vol. 9793, 97932H · C 2015 SPIE, IEEE, OSA, ICO · doi: 10.1117/12.2223216 


\section{Production volume of the Swiss photonics industry 2013 Total: 3 billion Swiss francs}

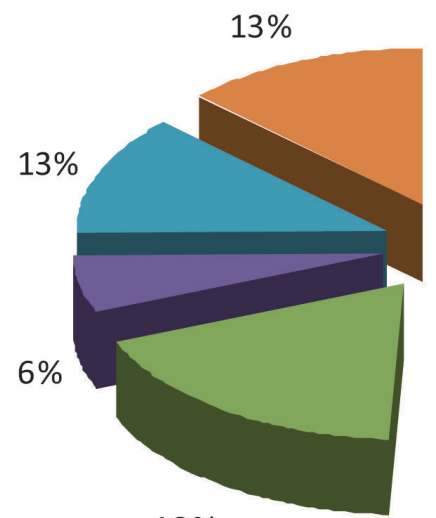

$18 \%$

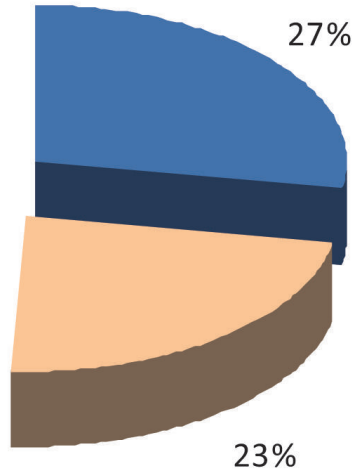

Laser material machining

Optical measurement techniques and image data processing

Optical medical engineering and life science

Optical information technology

Photovoltaics

Optical components and systems

\section{OPTECH CONSULTING}

Figure 1. Total production volume of the Swiss photonics industry 2013 (from Optech Consulting ${ }^{1}$ )

\subsection{Photonics organizations in Switzerland}

The importance of photonics was also recognized in Switzerland and Swissmem, the Swiss association of mechanical and electrical engineering industries, founded a new photonics group in $2013^{3}$. This group consists of members from industry, research institutions and universities with interest and business in the photonics field. Besides that, exists the Swiss national thematic network for photonics, Swissphotonics ${ }^{4}$, which has a close collaboration with Swissmem. In 2014, the photonics group of Swissmem started to discuss the lack of photonics engineers in the industry and their needs and wishes towards young academics. Different workshops were conducted with companies directly involved into photonics, as well as with companies producing and delivering systems and components in the photonics field. The finding of these workshops was that there is the need for a national bachelor program in photonics in Switzerland. The Swiss market potential was estimated to be between 25 to 50 students per year. Also there was a clear statement that the students should get a very broad photonics education and that the specialization can be done later on the job in the companies or in a master or advanced study program.

\subsection{Market analysis of industrial segments}

In parallel, the University of Applied Sciences HTW Chur conducted a market analysis to determine if the planed photonics bachelor program should be focused in a specific segment of the large photonics field. First, ten groups with technical fields were defined (see table below). 
Table 1: The ten groups of technical fields

\begin{tabular}{|c|l|}
\hline Group & Technical fields \\
\hline 1 & Sensor technology, optical systems, opto-technology, optoelectronics, automotive, microsystems, microelectronics \\
\hline 2 & Illumination, light technology, automotive lightning, display \\
\hline 3 & Image data processing, camera and vision, optical measurement techniques, photo technology \\
\hline 4 & Optics (lens design), microscopy, laser technique, \\
\hline 5 & Communication, optical fibers, information technology, computer technology, precision machining \\
\hline 6 & Life sciences, medical technologies, bio-photonics, biotechnologies \\
\hline 7 & Laser machining, manufacturing technology, robotic, automation, 3D laser printing, production technologies \\
\hline 8 & Photovoltaic, solar technology, thin film technology, material engineering, chemistry \\
\hline 9 & Aviation and space, defense, security, surveillance \\
\hline 10 & Research institutes, scientific measurement equipment, measurement and testing \\
\hline
\end{tabular}

In a next step, more than 50 Swiss companies (regional as well as national) were assigned to these ten different groups. A company can be assigned to multiple groups. The evaluation shows the distribution of the companies to these ten groups and can be interpreted as the market share.

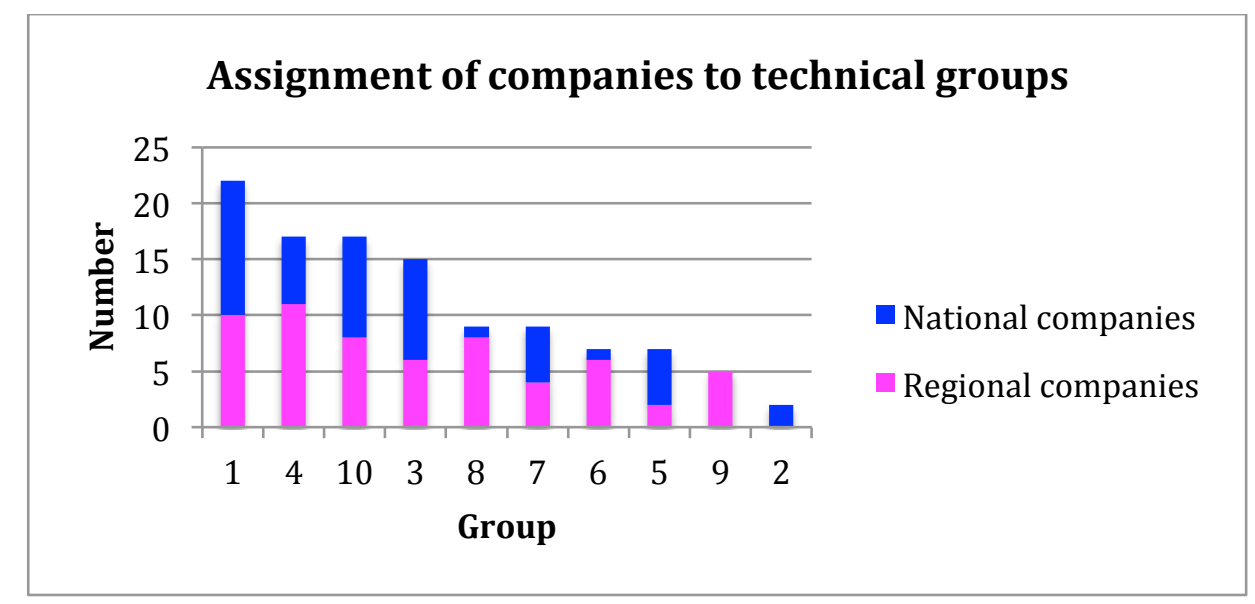

Figure 2. Number of regional and national companies for each technical group

The result of this analysis is used for the development of the curriculum (see section 4).

\section{UNIVERSITIES OF APPLIED SCIENCES IN SWISS EDUCATION}

\subsection{From apprenticeship to engineering degree}

Switzerland has a very successful dual education system. There exist two possibilities to get a bachelor or master degree. The following figure from the Swiss State Secretary for Education, Research and Innovation (SERI) ${ }^{5}$ shows the different education and training channels. 


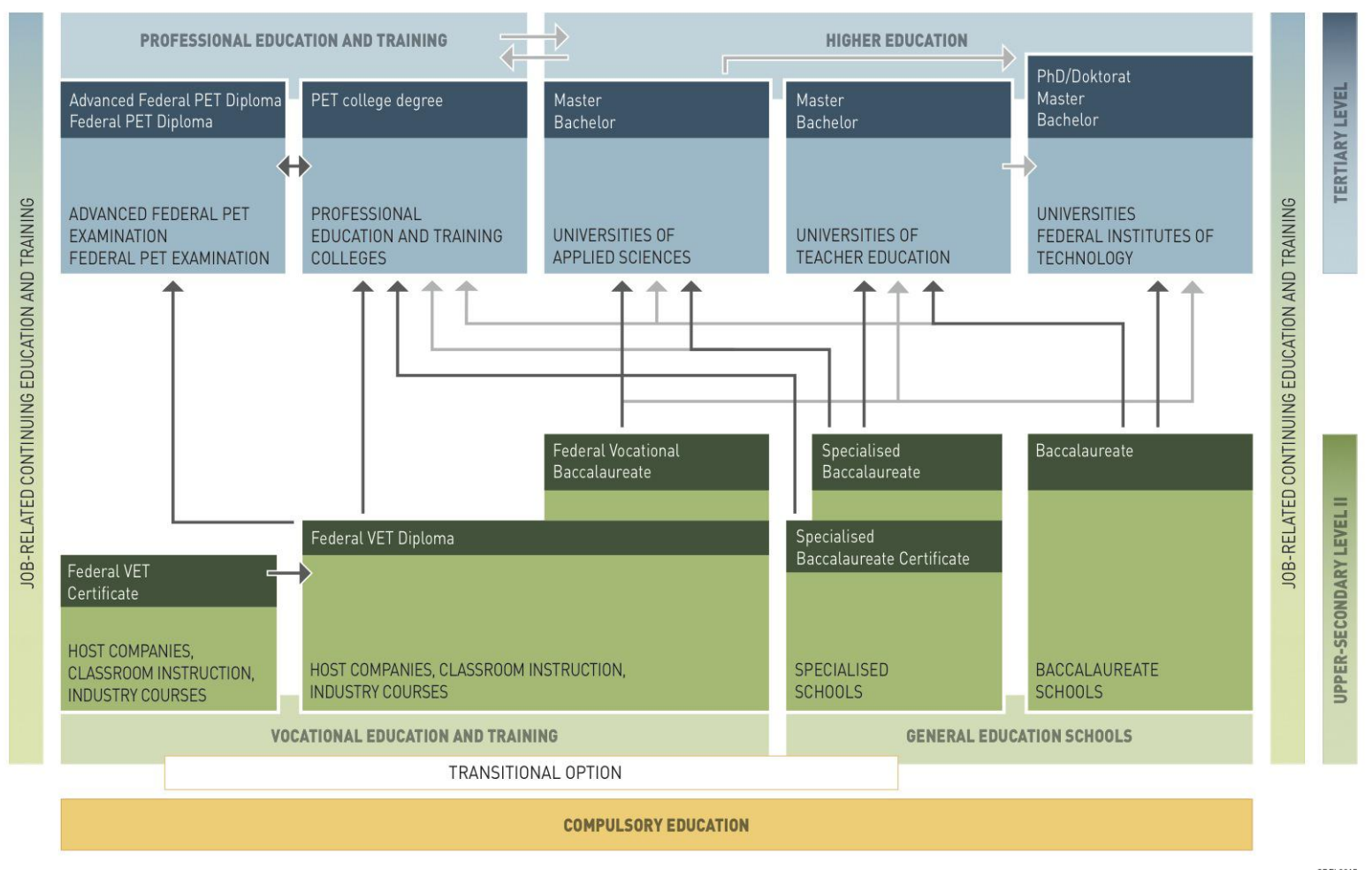

Figure 3. Swiss education system from SERI ${ }^{5}$

The first way is continuing in a baccalaureate school for another six years after the primary school (compulsory education) and finish with the "matura" degree (baccalaureate degree). This is very similar to the "abitur" in Germany. The baccalaureate degree is the qualification to enter the universities and federal institutes of technology. This path is shown on the right side in the figure above. On the other side, young people fulfill a total of nine years at school (6 years primary level and 3 years secondary level) and then start an apprenticeship, which takes 3 to 4 years depending on the profession. During this vocational education and training (VET), they learn the practical professional skills at a company while the theory is taught at a specialized school for each profession. After completion of the apprenticeship (federal VET diploma) and the federal vocational baccalaureate, they can enter a University of Applied Sciences in order to achieve a bachelor or master degree. This second path is shown in the middle of the figure above. This education track is more practical orientated since the engineers all complete an apprenticeship in a company whereas the engineers from the first education track typically have not yet worked in the industry before finishing their programs at universities. The discussed bachelor in photonics at the University of Applied Sciences HTW Chur belongs to the second education concept.

\subsection{Organization of the Swiss Universities of Applied Sciences}

In Switzerland two kinds of universities exist. On the first hand, the federal universities which require the matura degree to enter. On the other side, there exist many Universities of Applied Sciences, which belong to the second track of the education system, and one can enter a program with a finished apprenticeship and the necessary school marks. Both types offer bachelor as well as master degree programs in different fields. The students start in a bachelor program and can continue after the bachelor degree in a master program. One can state that the engineers from the federal universities have a more theoretical background and education while the programs of the Universities of Applied Sciences are more practical orientated. However, this in only a rough categorization and exceptions always exist. The share of students, which continue with a master program after their bachelor degree, depends on the universities type and the field. For the Universities of Applied Sciences, only about ten percent of the bachelor graduates continue with a master program. This matches very well with the industry demand regarding photonics engineers. The survey with Swissmem and the industrial companies clearly concluded that they need young academics with a bachelor degree from Universities of Applied Sciences. 


\section{BACHELOR IN PHOTONICS AT HTW CHUR}

\subsection{The University of Applied Sciences HTW Chur}

The University of Applied Sciences HTW Chur was founded in 1963 and is a member of the Universities of Applied Sciences of eastern Switzerland (FHO). With around 1600 students, the University of Applied Sciences HTW Chur is a regionally based university with national and international appeal. The HTW Chur provides an excellent learning environment with an intimate atmosphere, modern facilities, and small, student-oriented classes. The study courses offered include Bachelor, Master and further education courses in civil engineering/architecture, information science, business administration, multimedia production, system technology and tourism. In all these subjects, the HTW Chur is active in research and development and provides consultancy and other services. The complete university is certified according to ISO 9001:2008.

\subsection{Concept of the BSc in Photonics at HTW Chur}

The new bachelor in photonics program meets the increasing importance of photonics in general. The eastern part of Switzerland with the valley of the river Rhine is also called "Photonics valley". Many highly specialized companies from different photonics application fields are located in this region and develop here their future technologies for the world market. The general strategy of the HTW Chur is to offer bachelor degrees with a very strong focus on the practical training and the close connection to the industry and their applications. The concept is already implemented successfully for other programs and is based on the excellent network of the HTW Chur to the regional and national industry. The collaboration with these companies is a real partnership. The HTW Chur discussed the needs and requirements of these companies towards a future photonics engineer in detail and used the information as a basis for the curriculum development. Of course, the inputs from the Swissmem workshops were also taken into consideration. The companies support the HTW Chur by offering access to their special photonics equipment, by providing projects and bachelor themes, by organizing excursions, by promoting the bachelor program and most important, by teaching the students directly on some topics by their own specialists. This leads to a bachelor program with a strong connection to the industry that perfectly combines the theory with practical training and projects and guarantees the high quality level, which the HTW Chur requires from their graduates. It is the clear target of the HTW Chur to establish the first Swiss bachelor in photonics in which the students learn all the fundamentals of photonics and gain the necessary practical experience for their successful start in the industry.

\subsection{Job descriptions and application fields}

There are many industrial sectors with photonics applications. Some examples are optical sensors, laser machining and laser systems, optics and optical measurement equipment, lightning and illumination, surveillance and security, medical diagnostics and life science, robotics and automation, image data processing, automotive, camera and display techniques, communication technology and many more.

The photonics engineer can work in any of these fields, and can also choose from a variety of different job profiles such as development and research engineer, application engineer, product manager, sales engineer, measurement and quality control engineer or lightning and illumination designer. One can state that the job opportunities for a photonics engineer are a range so wide as that of light itself. 


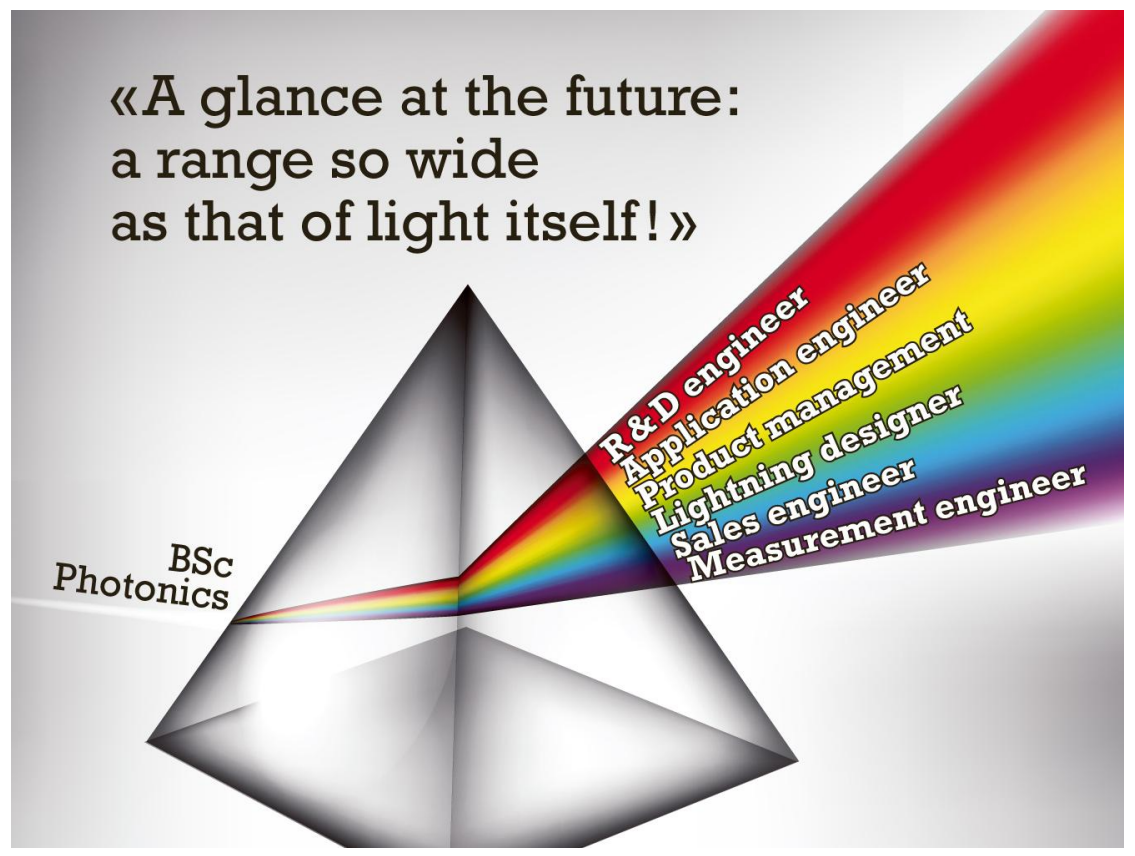

Figure 4. The job opportunities for photonics engineers: "a glance at the future: a range so wide as that of light itself!"

Four examples of possible job descriptions are given in more detail:

1. Optoelectronic, the combination of optics and semiconductors, is one of the key technologies of today's society. The applications range from automotive with increasing number and complexity of sensors to access control systems with retinal scanning systems. The combination of electronic hardware, software, mechanics and optics allows the optoelectronic engineers to develop and optimize electronic devices with optical components.

2. High-resolution camera chips and reliable displays with low power consumption are mandatory for smart phones and other devices. One of the enablers for such products is the image data processing engineer. He develops camera based sensor systems including the processing algorithm for two- and three-dimensional image data. These engineers understand the dependency between classical optics, illumination, data acquisition and real time evaluation.

3. Laser technique is the largest segment in the Swiss photonics market. The focused light is used for industrial material machining, medical diagnostics and surgery or in optical drives. The laser technique engineer develops and optimizes laser devices for these and many other applications. The power saving potential and the various design possibilities of the LED technology, create the need for more and more lightning design engineers.

4. Optical measurement methods have the huge advantage that they work contactless and non-destructive. Besides that, they can be used in harsh environments and, in combination with the appropriate optics, over long distances. One application field for the photonics engineers is the development and usage of optical measurement systems. The understanding of the fundamentals of the technology in combination with measurement and experimental setups and statistical methods enables them to properly run experiments and perform the analysis and interpretation of the results.

\section{CURRICULUM OF THE BSC IN PHOTONICS OF HTW CHUR}

\subsection{Overview of the curriculum}

The bachelor program is divided in six semesters as a full time study. A part-time study program will take eight semesters. The modules add up to 30 ECTS for each semester, leading to 180 ECTS for the complete degree. The figure below gives an overview of the curriculum of the bachelor in photonics at the HTW Chur. 


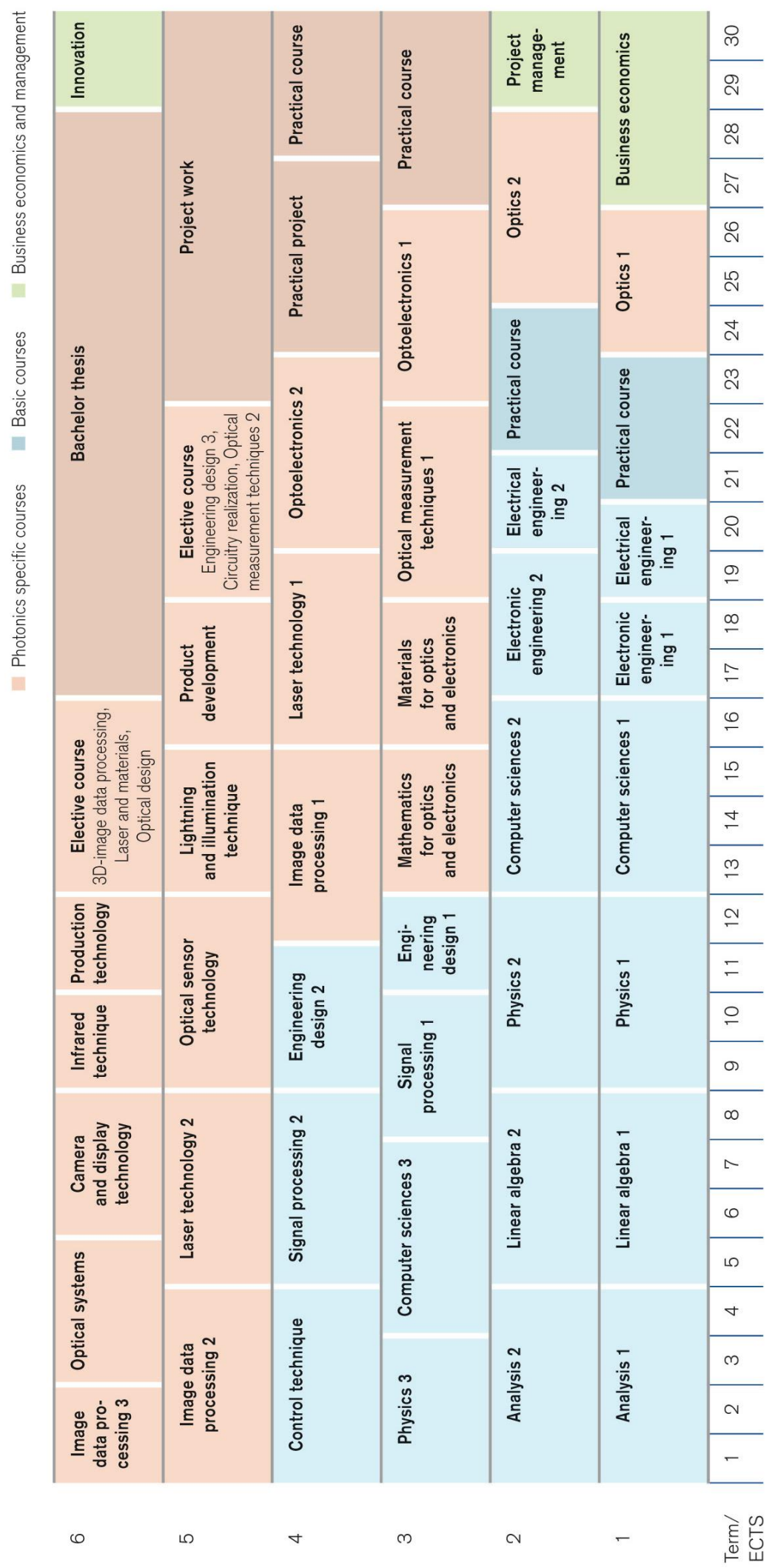

Figure 5. Curriculum of the first Swiss bachelor in Photonics at the University of Applied Science HTW Chur 
The program starts from the first semester with a specialization into photonics. The modules are grouped into three categories. Light blue marked are all the lectures that are basic courses but already have a clear preparation for the photonic specific modules in later semesters. The light orange marked modules are all photonic specific courses. The green courses are business economics and management modules. Almost $60 \%$ of all ECTS are assigned to photonic specific courses. With such a solid basis on the fundamentals of photonics, the curriculum clearly reflects the industrial needs. Besides the different colors, there is also a differentiation between light and dark marked modules. All dark modules are practical courses, project works or bachelor thesis. In the first four semesters, these are the practical courses, which contain experimental exercises in laboratories at the school itself or at the industrial partners. Practical project, project work and bachelor thesis in the later semesters are real industrial projects with a company from the photonic field. More than $20 \%$ of all ECTS are invested for practical courses or projects. This leads to the required practical experience in the photonics field, which is one of the quality goals of the HTW Chur for this bachelor program.

One will notice, that English courses are missing in the curriculum. Of course English is mandatory for today's engineers in photonics but no ECTS will be assigned to specific English lessons. However, the first certificate in English is required from the candidates at the time they finish the program in order to achieve their bachelor degree.

\subsection{Main focus}

The first two semesters are the assessment year. The focus is on the engineering fundamentals such as analysis, linear algebra, physics and computer sciences. These courses will also continue in the third semester. The electronic and electrical engineering modules in the first year are basis for the optoelectronic courses, which will follow in the second year. Optics is taught in the first two semesters in line with the physical basics. Business economics as well as project management are given already in the first year. Reason is that this mindset and knowledge is used for the practical projects in the fourth semester. In the third semester, other important categories are started. These are signal processing, mathematics and materials for optics and electronics and engineering design. Engineering design is followed by a second course in semester four, as is signal processing. Control technique rounds up the basic engineering courses. The focus of the fourth semester is set to the introduction of image data processing, a topic that continues until the end of the program. Engineering design is finished and the first part of laser technology is taking place, being followed by the second part in semester five. The goal of the last year is to give the students a broad overview of different photonic related topics from various application fields. It is obvious that no specialization on these technologies is possible in the given time frame, but in order to fulfill the industrial needs, the fundamentals should be discussed. An overview of optical sensors and different illumination techniques is given next to camera, display and other infrared techniques. The basics of fiber optics are discussed in the module optical systems. In product development, the students learn what general skills are needed by an engineer to develop products and interact with team members from different professions. The module production technology covers two topics: the usage of photonics in automation and production processes, as well as important specifications that must be taken into consideration when producing photonic devices. In the two elective courses in the last year, the student can choose between different modules to get a slight specialization in their field of interest. Innovation is the last course from the management category and prepares the students for their bright future in the various photonic fields.

\section{REFERENCES}

1. Optech Consulting, Dr. Arnold Mayer, "Photonik in der Schweiz, Wirtschaftliche Bedeutung", Untersuchung fuer SWISSPHOTONICS, November 2014, http://www.optech-consulting.com

2. Photonics Industry Report 2013, http://www.photonics21.org/download/Photonics industry report 2013/photonics industry report 2013.pdf

3. Photonics group of the Swiss association of mechanical and electrical engineering industries, http://www.swissmem.ch/en/organization-members/specialist-groups/photonics.html

4. Swiss national thematic network for photonics, Swissphotonics, http://www.swissphotonics.net/home.html

5. State Secretary for Education, Research and Innovation (SERI), http://www.sbfi.admin.ch/org/index.html?lang=en 